\title{
STUDY OF T-SCORE ACROSS DIFFERENT AGE GROUPS AND GENDER IN APPARENTLY HEALTHY POPULATION IN INDIA
}

\author{
Physiology
}

\section{Abhishek Sinha*} Rinku Garg
Associate Professor, Department Of Physiology, Santosh Medical College, Ghaziabad *Corresponding Author Professor, Department Of Physiology, Santosh Medical College, Ghaziabad

\section{ABSTRACT}

INTRODUCTION: Bone mineral density(BMD) is a common test done in our country. Traditionally, BMD has been reserved for postmenopausal females to check for risk of osteoporosis. The aim of this study is to check whether BMD score showed difference between males and females and across different age groups. Also, we tried to examine any correlation between Vitamin D and BMD values.

MATERIAL AND METHODS: It was a cross-sectional observational study.118 healthy subjects of both genders were recruited. BMD was measured by dual energy X-ray absorptiometry(DEXA). Vitamin D was estimated by electrochemiluminescence.

Statistical Analysis: Data was entered in to MS Excel and analyzed by STATA 12 software. Normality was analyzed. Mean and SD for all variables were calculated. Difference in T-score between males and females were calculated using T-test and T-score in different age groups was compared using one-way ANOVA test. Vitamin D levels were correlate with T-scores by Spearman's correlation test.

RESULTS: Mean age of subjects was 51.31 years. Mean T-score was -1.40. Mean Vitamin D was $23.45 \mathrm{ng} / \mathrm{ml}$. There was no significant difference between T-score of males and females. T-score was also not significantly different across age groups from 20 to 80 years. Vitamin D was not correlated with T-score in same subjects. Osteopenia was present in 74 subjects and osteoporosis in 11 subjects.

DISCUSSION: Contrary to popular opinion, T-score was not different between males and females, therefore there is a need for uniform BMD criteria for both genders. Vitamin D levels alone are unreliable as they do not correlate with T-score.

CONCLUSION: Thus, there is a need for revised T-score guidelines and additional tests like serum calcium, BMI, serum parathormone which needs to be done and examined together with BMD and Vitamin D to identify bone demineralization in the population.

\section{KEYWORDS}

Bone Mineral Density(bmd), T-score, Dexa Scan, Osteoporosis, Osteopenia, Vitamin D, Indian Population.

\section{INTRODUCTION}

It is a well known fact that bone mineral density decreases with increasing age especially in postmenopausal females ${ }^{1,2}$. At present, almost $10 \%$ of the Indian population is more than 50 years of age which is projected to increase to $16 \%$ in coming years ${ }^{3}$.Vitamin $\mathrm{D}$ is a hormone which plays an important role in absorption of calcium from intestine and bone mineralization. Its deficiency is associated with defects in bone mineralization. There is an alarming data regarding Vitamin D deficiency in Indian population with almost $80 \%$ of the population being deficient ${ }^{4}$.Fractures of bones especially hip fractures occur almost 10 years earlier in Indian population compared to western counterparts

Most of the studies classifying population as having osteoporosis has been based on measurement of bone mineral density(BMD) by dual energy X-ray absorptiometry (DEXA) technique and is reported as Tscore using the WHO reference values of T-score ${ }^{6}$. DEXA is based on the principle that low-dose $\mathrm{x}$-rays with two distinct energy peaks are sent through the bones being examined. One wavelength is absorbed mainly by soft tissue and the other by bone. The amount of soft tissue can thus be subtracted from the total to get the patient's bone mineral density in two dimensions ${ }^{12}$. T-score is defined as the number of standard deviations (SDs) of the patient's measured BMD from a reference peak BMD (PBMD) (mean BMD of gender-matched young adults). A $T$ score $\leq-2.5$ at any site is considered as diagnosis of osteoporosis and a score between -1 and -2.5 as osteopenia ${ }^{6}$.

It is important to remember that the BMD reference values in Indian population is different and lower than the WHO reference database $^{7,8}$. The cause for lower reference values in Indian population has been due to genetic differences, deficiency of nutrients like calcium, phosphate, Vitamin D and smaller skeletal size 9 .More specifically, Indians consume much lower amounts of calcium than the recommended intake 1 along with very frequent tea drinking ${ }^{10}$. Increased urbanisation also leads to bone demineralization by less physical activity, increased indoor living and less sun exposure ${ }^{11}$.Another concern is use of separate reference values for males and females BMD as young males have a higher bone density than young females ${ }^{12}$. But if the fracture risk is similar at same BMD in both genders then the use of gender specific database is not appropriate $^{13}$. International Osteoporosis Foundation ${ }^{14}$ and Intern ational Society for Clinical Densitometry (ISCD) ${ }^{15}$ have recommended the use of female young normal data to derive femoral neck T-scores in men. The ISCD Position Development Conference in 2013 recom mended to use NHANES III data as the reference standard "A uniform Caucasian (non-race adjusted) female reference database should be used to calculate T-scores for men of all ethnic groups"16.

With these changes in T-score reference standards in mind, the aim of this study was to check for variation in T-score between apparently healthy males and females and also to check for variation in T-score among different age groups from 20 years to 80 years in Indian population and try to see if a correlation between Vitamin D levels and T-score exists in an apparently healthy population.

\section{MATERIALAND METHODS}

It was observational cross-sectional study where healthy volunteers were recruited to a DEXA camp organised in an urban outpatient department. Written informed consent was taken from the subjects. A total of 118 subjects volunteered for the study. Institutional Ethical clearance was obtained prior to the initiation of the study. A general physical examination along with personal details was noted for each subject. Age was taken as number of years completed as reported by the subjects. Height was measured using a standard stadiometer with the subject standing in erect posture with the heel and back against the wall without footwear. Bone densitometry was done by DEXA scan. DEXA scan was conducted using an Osteosys SONOST 2000 machine. Right foot was placed on the foot stand in the machine and measurements of calcaneal bone density were taken for all 118 subjects. To ensure uniformity the operator for all the tests remained same. The T-score was calculated using the machine software and reported using the WHO reference values. Vitamin D was measured by electrochemiluminescent protein binding assay intended for the quantitative determination of total $25-\mathrm{OH}$ vitamin $\mathrm{D}$. The assay employs a vitamin D binding protein (VDBP) as capture protein, which binds to both 25-OH D3 and 25-OH D2 (Roche Diagnostics, Mannheim, Germany)

\section{STATISTICALANALYSIS}

Data was entered in to MS Excel and analyzed by STATA 12 software StataCorp. 2011. Stata Statistical Software: Release 12. College Station, TX: StataCorp LP.

Normality was analyzed. Mean and SD for all variables were calculated. Difference in T-score between males and females were calculated using t-test and T-score in different age groups (20-39 years, $40-59$ years, $60-79$ years , 80-100 years) was compared using one-way

ANOVA test. Vitamin D levels were correlated with T-scores by 
Spearman's correlation test. The study population was classified in to normal, osteopenia and osteoporosis using WHO reference values.

\section{RESULTS}

As shown in Table 1 the mean age was 51.3114 .05 years with the range of 23 to 86 years. The mean value of BMD recorded by T-score was 1.400.72 with the lowest value as -2.9 and highest value as 0.1 .Vitamin D levels had a mean value of $23.4516 .01 \mathrm{ng} / \mathrm{ml}$ with the lowest value of $5.64 \mathrm{ng} / \mathrm{ml}$ and highest value of $63.2 \mathrm{ng} / \mathrm{ml}$

There was no significant difference between the T-scores in males and females as shown in Table 2 by T-test. Next the entire study population was classified in to groups of 4 groups of 20-39 years, 40-59 years, 6079 years , 80-100 years and T-score of these groups were compared to each other by one-way ANOVA. As depicted in Table 3, there was no significant difference between the T-score across these groups. Finally the study population was divided according to WHO reference values for T-score where $28 \%$ had normal bone density, $63 \%$ were classified in to osteopenia and $9 \%$ were classified in to osteoporosis as depicted in Figure 1.Finally Vitamin D levels were correlated with T-scores in the same individuals in the study population using Spearman's correlation. No significant correlation was observed.

Table 1. Summary of values of age, T-score \& Vitamin D in study population

\begin{tabular}{|l|l|l|l|}
\hline Variable & MeanSD & Minimum & Maximum \\
\hline Age(years) & 51.3114 .05 & 23 & 86 \\
\hline T-score & -1.400 .72 & -2.9 & -0.1 \\
\hline Vitamin D ( ng/ml) & 23.4516 .01 & 5.64 & 63.2 \\
\hline
\end{tabular}

Table 2. T-scores in males versus females in study population

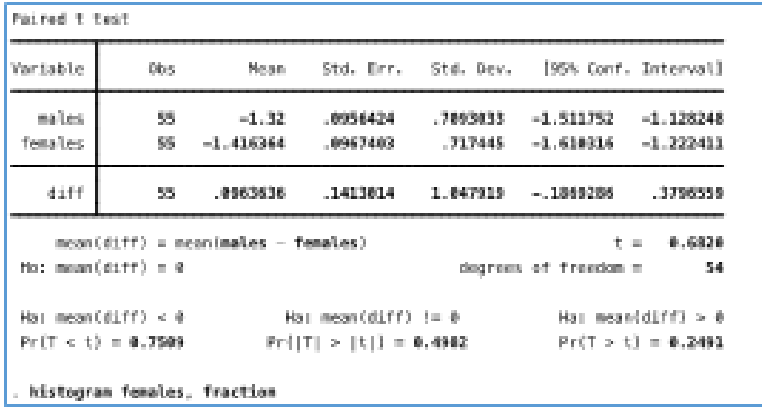

Table 3. One- way ANOVA showing comparison across T-score in different age groups(20-39 yrs, 40-59 yrs, 60-79 yrs, 80-100 yrs)

\begin{tabular}{|l|l|l|l|l|l|}
\hline & Sum of squares & df & Mean square & F & Sig \\
\hline $\begin{array}{l}\text { Between } \\
\text { groups }\end{array}$ & 1.0955 & 3 & 0.3652 & 0.69061 & 0.559564 \\
\cline { 1 - 4 } $\begin{array}{l}\text { Within } \\
\text { groups }\end{array}$ & 61.3344 & 116 & 0.5287 & & \\
\cline { 1 - 4 } Total & 62.4299 & 119 & & & \\
\hline
\end{tabular}

Table 4. Spearman's Correlation between Vitamin D and T-score values in study population

\begin{tabular}{|l|l|}
\hline Number of observations & 30 \\
\hline rs & -0.2184 \\
\hline $\mathrm{P}(2$-tailed $)$ & 0.4003 \\
\hline
\end{tabular}

Figure 1. Prevalence of alterations in BMD in study population.

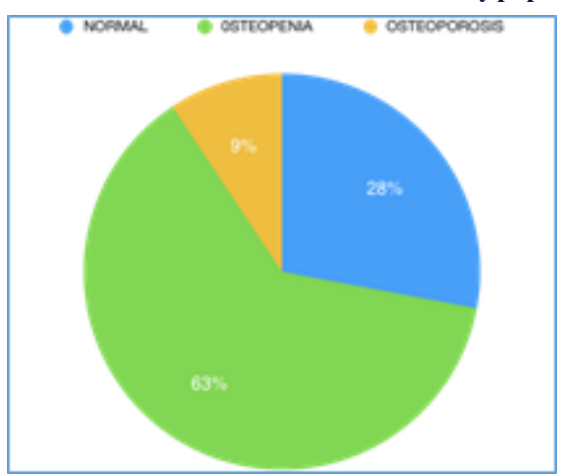

DISCUSSION

The BMD was estimated at heel calcaneal bone, it has been shown that BMD values of calcaneal bone correlates with hip and spine measurements ${ }^{20}$. As can be seen in results, the study population was divided according to $\mathrm{WHO}$ reference values for T-score where $28 \%$ had normal bone density, $63 \%$ were classified in to osteopenia and $9 \%$ were classified in to osteoporosis. The large percentage of population $63 \%$ who were apparently healthy but were classified in to osteopenia and $6 \%$ in to osteopororsis agrees with the statistics reported by other authors in Asia ${ }^{18}$, India ${ }^{1}$ and North India ${ }^{2}$.The mean age of our study population was 51.3114 .05 years which is representative of the age group in whom bone density is usually studied, the range of population was 23 years to 86 years which shows that the study sample was a heterogeneous sample whose results can be extrapolated to the general population. The BMD denoted by T-score had a mean value of 1.400 .72 for the study population which shows that majority of study population had low bone mineral density. These findings have been corroborated by multiple authors ${ }^{19,21,22}$ in Indian population. Vitamin D had a mean value of $23.4516 .01 \mathrm{ng} / \mathrm{ml}$. As Vitamin D level of 20-30 $\mathrm{ng} / \mathrm{ml}$ is defined as Vitamin D insufficiency and less than $20 \mathrm{ng} / \mathrm{ml}$ is defined as deficiency ${ }^{23}$, we can see that the majority of population had Vitamin D insufficiency which is collaborated by other authors ${ }^{4,11,24}$. The study population had 63 males and 55 females which again shows that the data represents the values of both genders equally.

When the T-scores between males and females were compared in our study population was compared no significant difference was found in spite of the well known fact that T-score in postmenopausal females decreases more than men by using a female specific reference scale $^{6}$. This finding is in agreement with the fact that in recent times it has been recommended that the same scale be used for both males and females as both genders ${ }^{16}$ have the same risk of fractures at same $\mathrm{BMD}^{25}$. Thus there is a need for a uniform reference scale for both males and females in the population as shown in our study because there is no significant difference between the T-score of the two genders in our study, this is supported by other authors also $^{26}$. Conversely other authors do not advocate the use of a single reference value for both males and females as it grossly underestimates the risk of osteoporosis in males ${ }^{27}$.

Then the entire study population was classified in to groups of 4 groups of 20-39 years, 40-59 years, 60-79 years, $80-100$ years and T-score of these groups were compared to each other by one-way ANOVA, there was no significant difference between the T-score across these groups which shows that T-scores do not vary significantly from $20-80$ years. This is in sharp contradiction to various studies which have shown a decrease in T-score fro before 50 years to after 50 years $^{22}$ and another study which shows a fall in BMD every 10 years ${ }^{19}$. The reason for no significant fall in our study may be due to the heterogeneous population comprising of both males and females less percentage of population in more than 50 years age group and the apparently healthy population with no symptomatic bony complaints. Further, we tried to correlate the Vitamin D levels with T-scores in the same individuals but again no significant correlation was seen. This is in agreement with another study where no correlation was noted between Vitamin D and $\mathrm{BMD}^{24}$

\section{CONCLUSION}

Thus, there is a need for revised and uniform T-score guidelines for estimating BMD in both males and females in the population and additional tests like serum calcium, BMI, serum parathormone which needs to be done and examined together with BMD and Vitamin D to identify bone demineralization in the population.

\section{LIMITATIONS OFTHE STUDY}

As the study population belonged to affluent socioeconomic study, a study involving low socioeconomic status population should be done. A prospective follow up study in the same individual would give a better picture of change in BMD. A bigger sample size of 500 to 1000 subjects would again give a more holistic picture of the population. The heterogeneous nature of the population comprising of both males and females, less percentage of population in more than 50 years age group and the apparently healthy population with no symptomatic bony complaints all contribute to not much change in the BMD in our study. Further studies with large sample size and specified age groups are needed to validate these results.

\section{ACKNOWLEDGEMENT}

The authors would like to acknowledge the indispensable role and 
profound experience of Dr Purushottam Narayan Sinha in the recruitment, examination and data collection of the patients. The authors declare no conflict of interest for this study. No funding was obtained for this study.

\section{REFERENCES}

1. Shatrugna V, Kulkarni B, Kumar PA, Rani KU, Balakrishna N. 2005.Bone status of Indian women from a low income group and its relationship to the nutritional status. Osteoporos Int; 22(11): 1827 .

2. Marwaha RK, Tandon N, Garg MK, Kanwar R, Narang A,Sastry A, Saberwal A, Bhadrak \& Mithal A.2011. Bone health in healthy Indian population aged 50 years and above. Osteoporos Int;22(11):2829-2836.

3. Government of India, Ministry of Home Affairs 2011, Office of the Registrar General \& Census Commissioner, India, http://censusindia.gov.in

4. Bebyartseva M, Mithal A, Kaur P, Kalra S, Baruah MP, Mukhopadhyay S, Bantwal G \& Bandgar TR.2012. Widespread Vitamin D deficiency among Indian healthcare professionals. Arch Osteoporosis; 7(1-2):187-192.

5. Malhotra N \& Mithal A.2008.Osteporosis in Indians. Indian J Med Res;127(3): 263268.

6. Assessment of fracture risk and its application to screening for postmenopausal osteoporosis. Report of WHO study group. World Health Organ Tec Rep Ser. 1994; 843: $1-129$

7. Population based reference standards of peak bone mineral density of Indian males and females: An ICMR multi-center task force study.2010; New Delhi: ICMR Publication; Published by Director General: 1-24.

8. Paul T, Asha HS,Mahes DM,Naik D,Rjaratnam S,Thomas N \& Seshadri MS.2012.The diagnosis of osteoporosis among subjects of southern Indian origin above 50 years of age.The impact of Indian Council of Medical Research versus Caucasian bone mineral density reference standards.Indian J Endocrinol Metab;16(2):S514-S524

9. Shivane V, Sarathi V, Lila A, Bandgar T, Joshi S, Menon P \& Shah N.2012.Peak bone mineral density and its determinants in an Asian Indian population. J Clin Densitom: Assessment of skeletal health: 15(2): 152-158

10. Jha R, Mithal A, Malhotra N \&Brown E.2010.Pilot case control investigation of risk factors for hip fractures in the urban Indian population. BMC Musculoskelet Disord;11:49.

11. Harinarayam CV, Ramalakshmi T \&Prasad UV. 2007.High prevalence of low dietary calcium, high phytate consumption and Vitamin D deficiency in healthy south Indians. Am J Clin Nutr; 85: 1062-1067.

12. Lorente Ramos RM, et al. Absorciometría con rayos X de doble energía. Fundamentos, metodología y aplicaciones clínicas. Radiología. 2012;54:410-23.

13. Binkley N, Schmeer P, Wasnich RD, et al. What are the criteria by which a densitometric diagnosis of osteoporosis can be made in males and non-Caucasians? J Clin Densitom. 2002; 5(suppl):S19-S27.

14. Kanis JA, Bianchi G, Bilezikian JP, et al. Towards a diagnostic and therapeutic consensus in male osteoporosis. Osteoporos Int. 2011;22:2789-2798.

15. Hans PDD, Downs RW, Duboeuf F, et al. Skeletal sites for osteoporosis diagnosis: The 2005 ISCD Official Positions. J Clin Densitom. 2006; 9:15-21.

16. Watts NB, Leslie WD, Foldes AJ. International Society for Clinical Densitometry Position Development Conference: Task Force on Normative Databases. J Clin Densitom. 2013; 16:472-481.

17. Cobas E411 Vitamin D Total Reagent Insert (06268668001V1) Roche Diagnostics Web site. http://www captodayonline.com/productguides/instruments/automatedimmunoassay-analyzers-july-2012/roche-diagnostics-cobas-e411-immunoassayanalyzers-june-2011.html.

18. 'Osteoporosis in Asia: a call to action' 2012, Curr Osteoporos Rep;10(4):245-247

19. Mujeeb, et al.: Age Specific Bone Mineral Density Values from Multi-Skeletal Sites in Normal Indian Female Population. International Journal of Scientific Study. January 2017; 4(10): 62-66.

20. Salminen H, Sääf M, Ringertz H, Strender LE. Bone mineral density measurement in the calcaneus with DXL: comparison with hip and spine measurements in a crosssectional study of an elderly female population. 2005. Osteoporos Int. 16(5):541-51. Epub 2004 Sep 21

21. Cherian KE, Kapoor N, Asha HS, Thomas N, Paul TV. Influence of different reference databases on categorization of bone mineral density: A study on rural postmenopausal databases on categorization of bone mineral density: A study on ru

22. Kadam NS, Chiplonkar SA, Khadilkar AV, Khadilkar VV. Prevalence of osteoporosis in apparently healthy adults above 40 years of age in Pune City, India. Indian J Endocr Metab 2018;22:67-73.

23. Holick MF. Vitamin D status: Measurement, interpretation, and clinical application. Ann Epidemiol. 2009;19:73-8.

24. Kaminemi V, Latha AP, and Ramathulasi K. Association between serum 25hydroxyvitamin D levels and bone mineral density in normal postmenopausal women.2016. J Midlife Health Oct-Dec. 7(4): 163-168.

25. Binkley N, Schmeer P, Wasnich RD, et al. What are the criteria by which a densitometric diagnosis of osteoporosis can be made in males and non-Caucasians? J Clin Densitom. 2002; 5(suppl): S19-S27.

26. Binkley N, Adler R, and Bilezikian JP. Osteoporosis Diagnosis in Men: The T-score Controversy Revisited. 2014. Curr Osteoporos Rep. December; 12(4): 403-409.

27. Faulkner KG, Orwoll E. Implications in the Use of T-Scores for the Diagnosis of Osteoporosis in Men. 2002. Journal of Clinical Densitometry; 5(1) : 87-93. 